\title{
Ação antagônica e de metabólitos bioativos de Trichoderma spp. contra os patógenos Sclerotium rolfsii e Verticillium dahliae
}

\author{
Carolina Oliveira Isaias, Irene Martins, João Batista Tavares da Silva, Joseane Padilha da Silva, Sueli Corrêa \\ Marques de Mello
}

Embrapa Recursos Genéticos e Biotecnologia, Parque Estação Biológica - W5 Norte (final), Asa Norte, CEP 70.770-917, Brasília, DF

Autor para Correspondência: Sueli Corrêa Marques de Mello (sueli.mello@embrapa.br)

Data de chegada: 10/10/2013. Aceito para publicação em: 03/02/2014.

\section{RESUMO}

Isaias, C.O.; Martins, I.; Silva, J.B.T.; Silva, J.P.; Mello, S.C.M. Ação antagônica e de metabólitos bioativos de Trichoderma spp. contra os patógenos Sclerotium rolfsii e Verticillium dahliae. Summa Phytopathologica, v.40, n.1, p.34-41, 2014.

O efeito antagônico exercido por fungos do gênero Trichoderma foi avaliado contra os fitopatógenos Sclerotium rolfsii e Verticillium dahliae, isolados de áster ornamental e morangueiro, respectivamente. Utilizaramse 20 isolados do antagonista, pertencentes às espécies T. asperellum, $T$. hamatum, T. harzianum, T. koningiopsis, T. spirale e Trichoderma sp. O antagonismo foi verificado por meio de testes de culturas pareadas e produção de metabólitos bioativos pelo método de sobreposição de placas. A maioria dos isolados exibiu efeito inibitório sobre o crescimento micelial de $S$. rolfsii e $V$. dahliae quando comparado com as testemunhas. Excetuando-se os testes de produção de metabólitos não-voláteis, verificou-se maior ação inibitória contra $V$. dahliae. Mesmo os metabólitos não-voláteis termoestáveis apresentaram efeito inibitório contra ambos os patógenos testados, mostrando que os metabólitos secundários do antagonista exercem efeito significativo sobre essas espécies patogênicas.

Palavras-chave adicionais: patógenos de plantas, fungo antagonista, controle biológico

\section{ABSTRACT}

Isaias, C.O.; Martins, I.; Silva, J.B.T.; Silva, J.P.; Mello, S.C.M. Antagonistic action and bioactive metabolites of Trichoderma spp. against the pathogens Sclerotium rolfsii and Verticillium dahliae. Summa Phytopathologica, v.40, n.1, p.34-41, 2014.

The antagonistic effect shown by fungi of the genus Trichoderma was assessed against the plant pathogens Sclerotium rolfsii and Verticillium dahlia, isolated from ornamental aster and strawberry, respectively. Twenty isolates of the antagonist were employed; they belonged to the species T. asperellum, T. hamatum, T. harzianum, T. koningiopsis, T. spirale and Trichoderma sp. Antagonism was investigated by means of dual culture tests and bioactive metabolite production based on the overlapping plate method. Most selected isolates had an inhibitory effect on the mycelial growth of $S$. rolfsii and $V$. dahlia, compared to controls. Except for nonvolatile metabolite production tests, inhibitory action against $V$. dahliae was highest. Even the thermostable non-volatile metabolites showed inhibitory effect against both tested pathogens, evidencing that the secondary metabolites of the antagonist have a significant effect on these pathogenic species.

Additional keywords: plant pathogens, antagonistic fungus, biological control

Os fungos pertencentes ao gênero Trichoderma estão entre os mais estudados e utilizados como agentes de biocontrole de doenças vegetais em todo o mundo. Esses microrganismos de vida livre e altamente interativos no solo, nas superfícies radiculares e no interior dos tecidos vegetais (21) apresentam atividade antagônica contra fungos fitopatogênicos. A atividade de biocontrole pode ocorrer indiretamente, competindo por espaço e nutrientes, modificando as condições ambientais, produzindo antibióticos, inativando as enzimas do patógeno ou, diretamente, mediante o micoparasitismo $(5,12)$, que envolve eventos sequenciais complexos, incluindo reconhecimento, penetração e subsequente morte do hospedeiro (19).

Muitas espécies de Trichoderma são reconhecidamente produtoras de metabólitos secundários, voláteis e não-voláteis, os quais apresentam amplo espectro de ação antimicrobiana. É notável o envolvimento de linhagens dessas espécies fúngicas também na ativação de mecanismos de defesa da planta e na regulação do crescimento vegetal (29), além de atuarem na complexa interação entre microrganismos no ambiente (28). Dentre os metabólitos produzidos por Trichoderma spp. citam-se: ácido harziânico, alameticinas, antraquinonas, azafilonas, daucanas, harzialactonas, bisorbicillinoides, butenolides, tricholina, glisopreninas, ácido heptelídico, gliovirina, pironas, tricotecenos, isocianatos, trichosetina, viridina, peptaiboles, entre outros (18, 22). Tais metabólitos, cuja produção é atribuída a vários genes, são excretados nas fases de crescimento e esporulação e estão entre os produtos naturais mais importantes utilizados para inibir o crescimento de microrganismos $(3,30)$.

Verticillium dahliae Kleb é um fungo de solo que apresenta ampla distribuição geográfica, sendo capaz de infectar diversas espécies de plantas economicamente importantes como ornamentais, olerícolas e frutíferas (20). Esse patógeno pode induzir sintomas foliares e vasculares com declínio ou morte prematura da planta (11). No Brasil tem sido relatado em tomate, berinjela, jiló, algodão, morango, quiabo 
e é amplamente conhecido como agente causal da murcha-de-verticilio (23).

Sclerotium rolfsii Sacc, outro fungo habitante do solo, é responsável por podridões de raízes e do colo, murcha e tombamento de plântulas especialmente nas zonas tropical e subtropical (25). Esse patógeno, mundialmente distribuído, possui vasta gama de hospedeiros, incluindo espécies hortícolas, ornamentais, leguminosas, cereais forrageiras e daninhas (1) em 500 espécies botânicas (6).

O objetivo desse trabalho foi identificar isolados do gênero Trichoderma, produtores de metabólitos voláteis e não-voláteis, capazes de inibir o crescimento dos fungos Sclerotium rolfsii e Verticillium dahliae.

\section{MATERIAL E MÉTODOS}

\section{Origem dos isolados de Trichoderma}

Foram utilizados 20 isolados de Trichoderma pertencentes à Coleção de Microrganismos para o Controle de Fitopatógenos e Plantas Daninhas da Embrapa. Esses isolados, caracterizados pela região espaçadora transcrita (ITS) do rDNA, são das espécies T. asperellum (CEN747, CEN761 e CEN786), T. hamatum (isolado CEN693), $T$. harzianum (CEN691, CEN725, CEN732 e CEN779), T. koningiopsis (CEN698, CEN703, CEN718, CEN723, CEN739, CEN758, CEN759, CEN768, CEN776 e CEN785), T. spirale (CEN775) e Trichoderma sp. (CEN772), todos obtidos de solo/rizosfera da cultura de morango em área de Cerrado do Distrito Federal.

\section{Obtenção dos fitopatógenos}

Os isolados $S$. rolfsii e $V$. dahliae utilizados neste trabalho pertencem à Coleção de Fitopatógenos da Embrapa Hortaliças. Ambos foram obtidos de amostras de tecidos infectados de áster ornamental e morango, respectivamente, coletadas em Brazlândia-DF.

\section{Avaliação do antagonismo em cultura pareada}

O antagonismo dos isolados de Trichoderma contra $S$. rolfsii foi avaliado em confronto direto, utilizando o método de pareamento de culturas, de acordo com Dennis \& Webster (7). A multiplicação inicial, tanto dos isolados de Trichoderma quanto dos patógenos, foi realizada em placas contendo o meio de batata-dextrose-ágar (BDA), acondicionadas em incubadora (Fanem, mod. 347), a 25 ${ }^{\circ} \mathrm{C}$, fotoperíodo de $12 \mathrm{~h}$, por 5 dias. Discos (5 mm de diâmetro) retirados das culturas puras dos patógenos foram depositados a uma distância de $1,0 \mathrm{~cm}$ da borda em placas de Petri, contendo o mesmo meio. As culturas foram incubadas por $24 \mathrm{~h}$, no caso de $S$. rolfsii e por 10 dias para $V$. dahliae, nas mesmas condições descritas acima. Seguidamente, o antagonista foi posicionado no lado oposto ao patógeno.

As avaliações do crescimento micelial foram realizadas quando toda a superfície do meio apresentava-se colonizada pelo $S$. rolfsii no tratamento testemunha (patógeno cultivado na ausência do antagonista) e, no caso de $V$. dahliae, quando o crescimento na testemunha atingira aproximadamente a metade da placa, devido ao seu lento crescimento em meio artificial. Cada cultivo pareado foi realizado com quatro repetições. Os tratamentos foram distribuídos ao acaso na câmara de crescimento e, findo o período de cultivo, foram realizadas as avaliações, sendo os isolados de Trichoderma classificados quanto ao antagonismo, segundo a escala de Bell et al. (4). Ainda, as medidas de diâmetro das colônias foram tomadas com o auxílio de régua milimetrada.
Efeito inibitório de metabólitos voláteis e não-voláteis de Trichoderma spp.

O efeito inibidor de metabólitos voláteis foi testado conforme descrito por Dennis \& Webster (8). Duas bases de placas de Petri de $90 \mathrm{~mm}$ de diâmetro contendo BDA receberam, individualmente, discos ( $5 \mathrm{~mm}$ de diâmetro) das culturas do patógeno e do antagonista. Após $24 \mathrm{~h}$, as bases contendo antagonista e patógeno foram sobrepostas e unidas com filme de PVC. Como testemunha, foram sobrepostas duas bases contendo o patógeno. As placas foram incubadas a $25^{\circ} \mathrm{C}$, com fotoperíodo de $12 \mathrm{~h}$, de acordo com as descrições de MartinsCorder (16). Cada tratamento foi composto por quatro repetições em delineamento inteiramente casualizado.

Em relação aos metabólitos não-voláteis, os isolados de Trichoderma foram cultivados em frascos Erlenmeyer contendo 250 $\mathrm{mL}$ de meio líquido à base de batata-dextrose. A incubação ocorreu em agitador orbital a $150 \mathrm{rpm}$, a $25^{\circ} \mathrm{C}$, em ausência de luz, durante sete dias. Após esse período, a parte líquida foi coletada por filtração em papel de filtro e centrifugada a $6.081 \mathrm{~g}$. A fase líquida foi esterilizada em membrana de celulose $(0,45 \mu \mathrm{m})$ e incorporada ao meio BDA, na proporção de $25 \%(\mathrm{v} / \mathrm{v})$. Foram preparadas quatro placas com filtrado de cada antagonista, para cada patógeno. Discos de ágar $(5 \mathrm{~mm})$ retirados de culturas dos patógenos, foram depositados no centro de cada placa de Petri contendo meio BDA suplementado com filtrado de culturas do antagonista. As culturas assim preparadas foram incubadas a 25 ${ }^{\circ} \mathrm{C}$. A testemunha consistiu de cada patógeno cultivado na ausência de filtrados de culturas dos antagonistas.

As avaliações do crescimento micelial foram realizadas quando toda a superfície do meio foi colonizada pelo $S$. rolfsii nas placas testemunhas. Quanto ao $V$. dahliae, as avaliações foram realizadas quando a testemunha atingiu aproximadamente a metade da placa. Em todas as fases do experimento, as culturas foram incubadas em câmaras BOD a $25^{\circ} \mathrm{C}$, com fotoperíodo de $12 \mathrm{~h}$.

\section{Termoestabilidade dos metabólitos não-voláteis}

Os metabólitos não-voláteis produzidos por Trichoderma foram testados quanto à termoestabilidade, de acordo com a metodologia de Kupper et al. (14), modificada. Os procedimentos para cultivo, incubação e ensaios de avaliação foram conduzidos como descrito no item avaliação em cultura pareada, porém os filtrados de cultura foram submetidos a aquecimento a $121^{\circ} \mathrm{C}$ por $20 \mathrm{~min}$, antes de serem incorporados ao meio de cultivo.

\section{Análise estatística}

Para os dados de inibição dos patógenos $S$. rolfsii e $V$. dahliae, foi considerado primeiramente o desempenho dos isolados em cada tipo de metabólito (não-volátil, volátil e termoestável) por meio de diagramas de caixa (boxplot) para verificar a inibição mediana, além da dispersão de cada isolado na inibição dos patógenos. Adicionalmente, utilizaram-se ferramentas estatísticas para análise de agrupamentos, em que os isolados foram agrupados pelo algoritmo hierárquico de ligação média, utilizando como métrica a distância euclidiana. O número ótimo de grupos foi determinado por meio do algoritmo PAM (Partitioning Around Medoids) e o método do comprimento médio de silhueta - uma medida que compara a distância média de cada observação aos pontos de seu agrupamento e sua distância aos pontos do agrupamento vizinho. Esta medida varia entre - 1 e 1, e deve ser maximizada; considera-se que valores entre 0,51 e 0,70 desta medida, apontam uma estrutura de agrupamentos razoável, enquanto valores entre 0,71 e 1 indicam estrutura forte. Por fim, para cada isolado, realizou-se um teste de comparação de médias de metabólitos voláteis com não-voláteis e 
não-voláteis com termoestáveis através do teste de Tukey, considerando o nível de 5\% de significância estatística. Para desenvolvimento das análises adotou-se o programa de linguagem estatística R, livre para download no sítio http://www.r-project.org/.

\section{RESULTADOS}

\section{Avaliação do antagonismo em cultura pareada}

Nos testes de antagonismo observou-se inibição do crescimento micelial dos isolados de $S$. rolfsii e $V$. dahliae quando confrontados com os 20 isolados de Trichoderma (Tabela 1). O isolado CEN691 (T. harzianum) apresentou grau máximo (classe 1) de antagonismo da escala de Bell et al (4), inibindo totalmente o crescimento dos dois fitopatógenos. Esse isolado foi o único a exibir máximo de inibição de crescimento micelial do $S$. rolfsii in vitro. Para $V$. dahliae, apenas o isolado CEN775 (T. spirale), apresentou baixa atividade antagônica (classe 4), ao contrário dos outros 19 isolados de Trichoderma que apresentaram máximo de inibição (classe 1) neste pareamento.

Avaliação do efeito inibitório de metabólitos voláteis, nãovoláteis e não-voláteis termoestáveis produzidos por isolados de Trichoderma spp.

O resumo estatístico para os metabólitos voláteis, representados pelo boxplot da Figura 1A mostra que apenas os metabólitos produzidos pelos isolados CEN725 (T. harzianum), CEN776 (T. koningiopsis)

Tabela 1: Classificação dos isolados de Trichoderma quanto ao antagonismo exercido sobre Sclerotium rolfsii e Verticillium dahliae.

\begin{tabular}{|c|c|c|}
\hline \multirow[t]{2}{*}{ ISOLADOS } & \multicolumn{2}{|c|}{${ }^{*}$ Classe } \\
\hline & S. rolfsii & V. dahliae \\
\hline CEN691 & 1 & 1 \\
\hline CEN693 & 3 & 1 \\
\hline CEN698 & 3 & 1 \\
\hline CEN703 & 3 & 1 \\
\hline CEN718 & 3 & 1 \\
\hline CEN723 & 3 & 1 \\
\hline CEN725 & 3 & 1 \\
\hline CEN732 & 3 & 1 \\
\hline CEN739 & 3 & 1 \\
\hline CEN747 & 2 & 1 \\
\hline CEN758 & 4 & 1 \\
\hline CEN759 & 4 & 1 \\
\hline CEN761 & 4 & 1 \\
\hline CEN768 & 4 & 1 \\
\hline CEN772 & 4 & 1 \\
\hline CEN775 & 4 & 4 \\
\hline CEN776 & 4 & 1 \\
\hline CEN779 & 4 & 1 \\
\hline CEN785 & 3 & 1 \\
\hline CEN786 & 3 & 1 \\
\hline
\end{tabular}

*Classificação em conformidade com a escala de Bell et al. (1982). e CEN786 (T. asperellum) apresentaram inibição de S. rolfsii significativamente superior a $60 \%$, enquanto em relação aos outros isolados o percentual de inibição do crescimento micelial ficou entre $40 \%$ e $60 \%$. Analisando a similaridade entre todos os isolados, o algoritmo PAM estimou a formação de dois grupos, sendo o primeiro contendo apenas a testemunha e o segundo, os demais isolados (Figura 2A). Quanto a $V$. dahliae, todos os isolados de Trichoderma testados mostraram desempenho semelhante, com ação inibitória próximo a $80 \%$. Na testemunha não houve alteração no crescimento do Verticilium (Figura 1B). Novamente, o algoritmo PAM mostrou a separação da testemunha dos demais isolados. Em ambas as análises de similaridade, o comprimento médio da silhueta foi maior que 0,70 , mostrando forte estrutura de formação dos grupos estimados (Figuras 2A, 2B).

Em relação aos metabólitos não-voláteis, os isolados CEN725 ( $T$. harzianum) e CEN768 (T. koningiopsis) foram os que apresentaram os

A
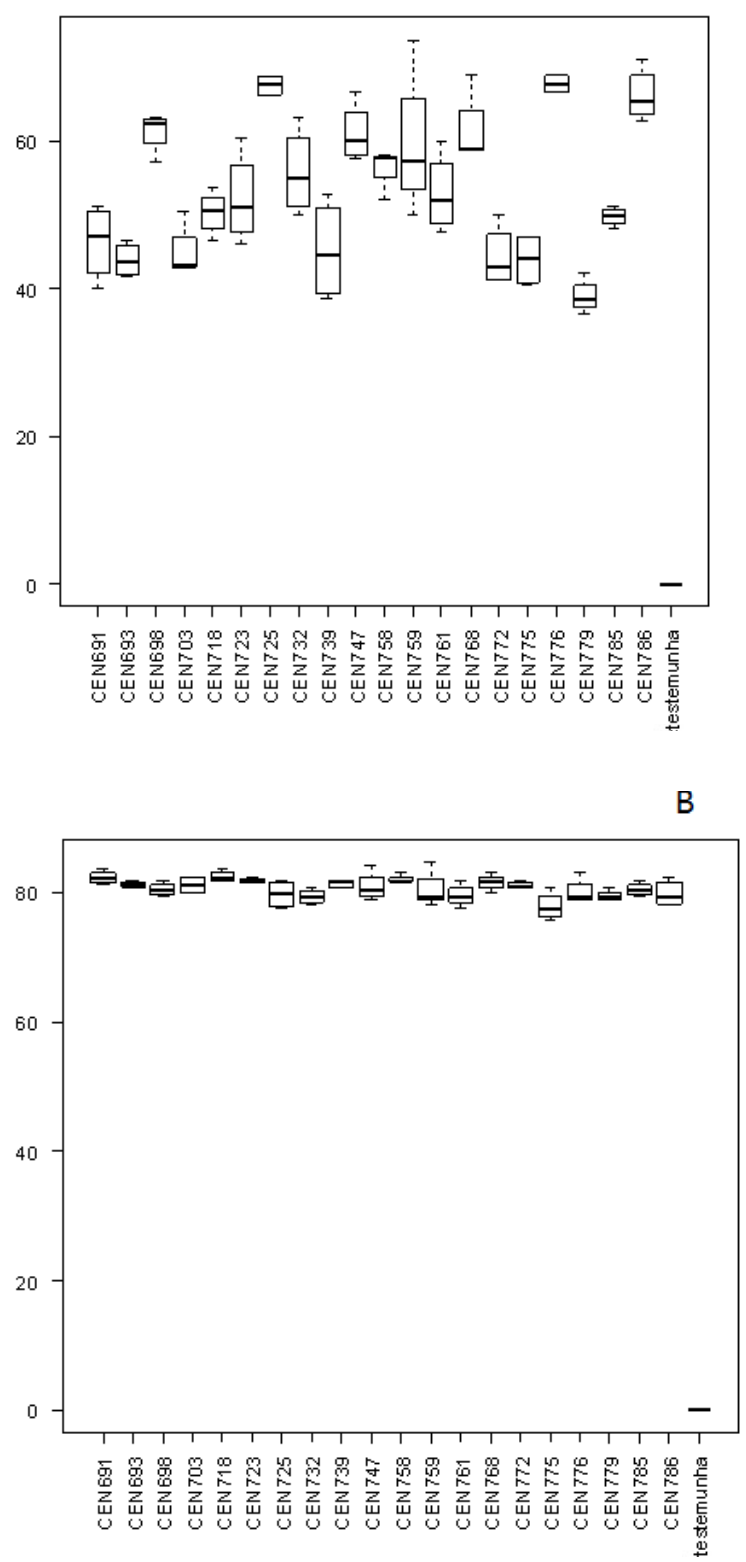

Figura 1. Boxplot do percentual de inibição de Sclerotium rolfsii (A) e Verticillium dahliae (B) por metabólitos voláteis produzidos por isolados de Trichoderma. 


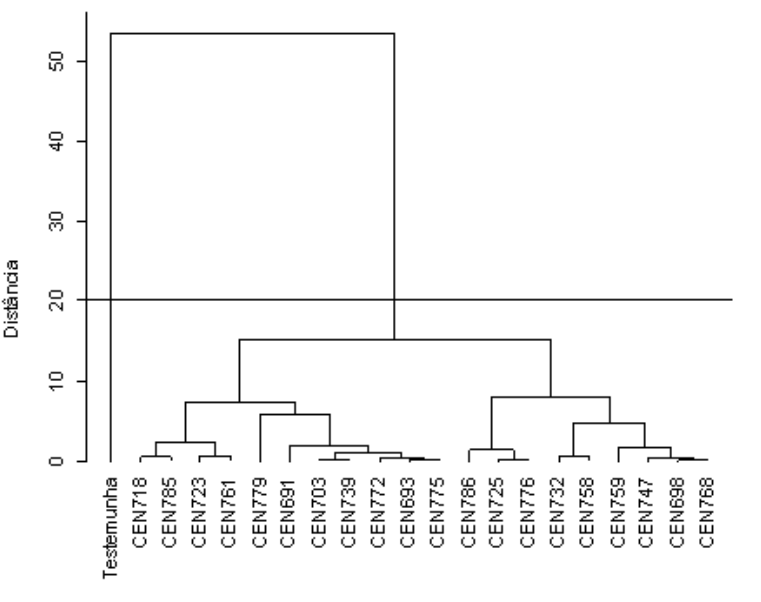

Comp. médio de silhueta: 0,7636 hclust (*, "average")

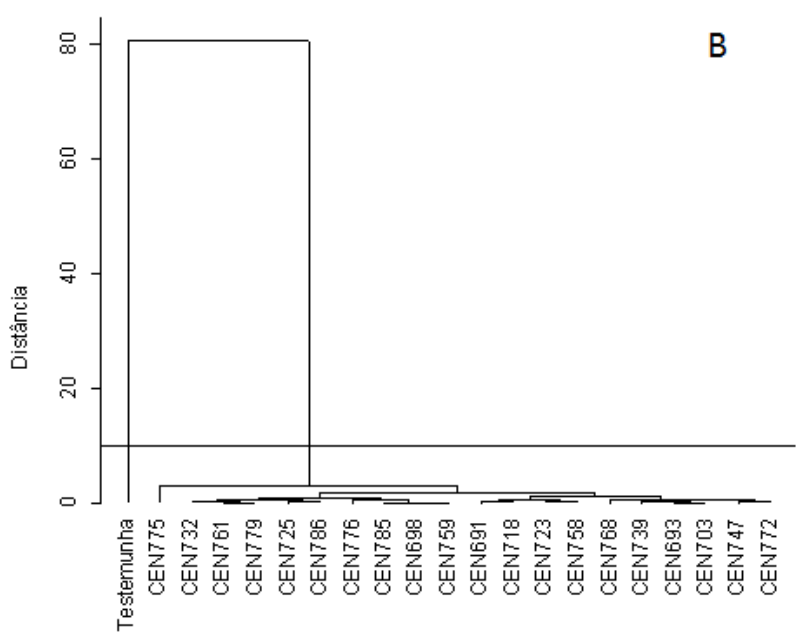

Comp. médio de silhueta: 0,9366 hclust (", "average")

Figura 2. Dendograma do agrupamento dos isolados de Trichoderma que inibiram Sclerotium rolfsii (A) e Verticillium dahliae (B) pela produção de metabólitos voláteis.

melhores resultados, com os seus metabólitos inibindo completamente o crescimento de $S$. rolfsii, já CEN698 e CEN703 (T. koningiopsis) e CEN772 (Trichoderma spp.) mostraram performances semelhantes, com aproximadamente $60 \%$ de inibição do patógeno, enquanto os isolados CEN691, CEN732, CEN779 (T. harzianum), CEN775 ( $T$. spirale) e CEN785 (T. koningiopsis) não mostraram ação inibitória (Figura 3A). O algoritmo PAM estimou 6 grupos para esses isolados $\mathrm{e}$ o comprimento médio da silhueta $(0,76)$ indicou boa qualidade nessa formação (Figura 4A). Em relação $V$. dahliae, o isolado CEN768 (T. koningiopsis) inibiu completamente o crescimento do patógeno, enquanto CEN698 (T. koningiopsis) apresentou a segunda maior proporção de inibição, em torno de $70 \%$. Em seguida, aparecem os isolados CEN747, CEN761 e CEN786 (T. asperellum), com taxas de inibição próximas de 55\% (Figura 3B). O algoritmo PAM também estimou a formação de 6 grupos com estrutura razoável, segundo o comprimento médio de silhueta $(0,62)$; dois dos grupo são constituídos por apenas um isolado cada, CEN768 e CEN698 (Figura 4B).

Para os metabólitos não-voláteis termoestáveis, os isolados CEN747 e CEN786 (T. asperellum), CEN698 e CEN768 (T. koningiopsis), apresentaram inibição de $S$. rolfsii superior a 50\% (Figura 5A). Destes, CEN768 e CEN786 são os isolados que apresentaram maior inibição. O algoritmo PAM estimou a existência de 4 grupos, cuja estrutura é fortemente sustentada pelo comprimento da silhueta $(0,7951)$, observada na Figura 6A. Quanto a V. dahliae, o isolado CEN698 mostrou o melhor desempenho na inibição do patógeno, seguido pelos isolados CEN747 e CEN768 com inibição em torno de 60\%, e os isolados CEN761 e CEN786 (T. asperellum), com aproximadamente $54 \%$ de inibição, conforme mostra o boxplot da Figura 5B. Quanto à similaridade desses isolados, o PAM estimou dois grupos. Notadamente, a separação ocorreu entre os isolados com inibição abaixo de $40 \%$ e

A
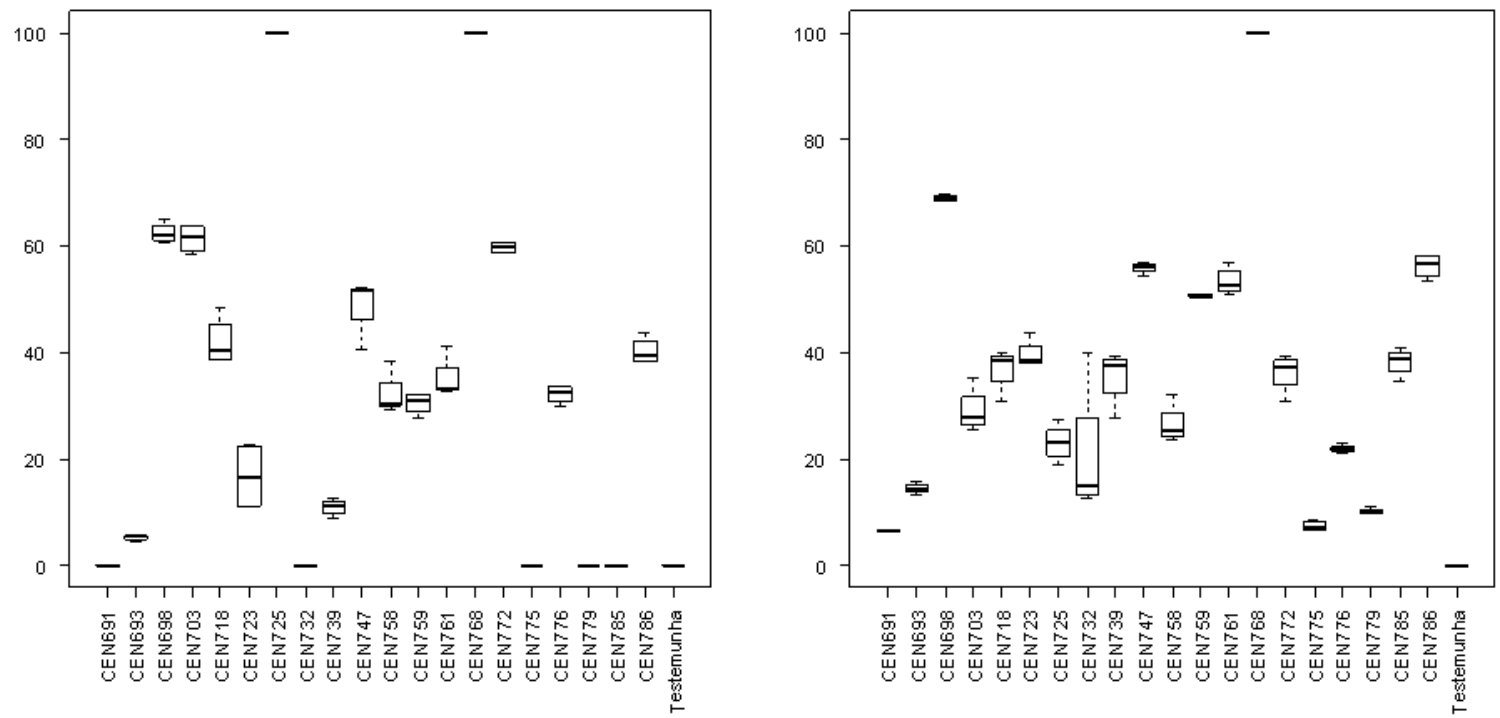

Figura 3. Boxplot do percentual de inibição de Sclerotium rolfsii (A) e Verticillium dahliae (B) por metabólitos não-voláteis produzidos por isolados de Trichoderma. 


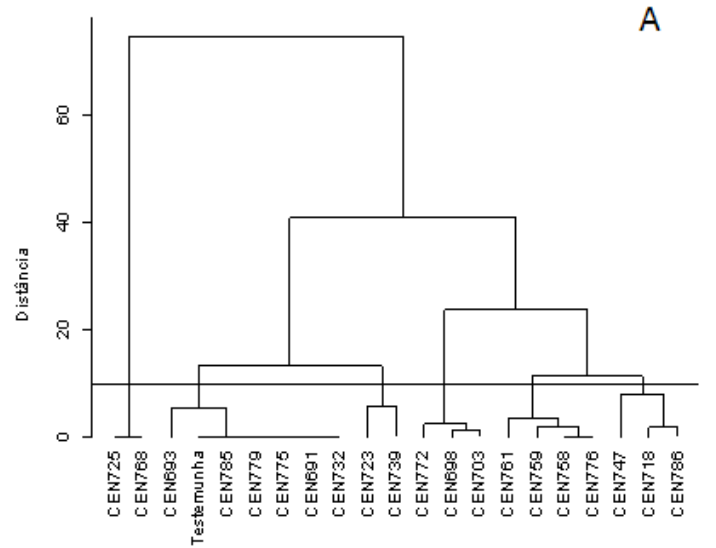

Comp. médio de silhueta: 0,7684 holust( (". "average")

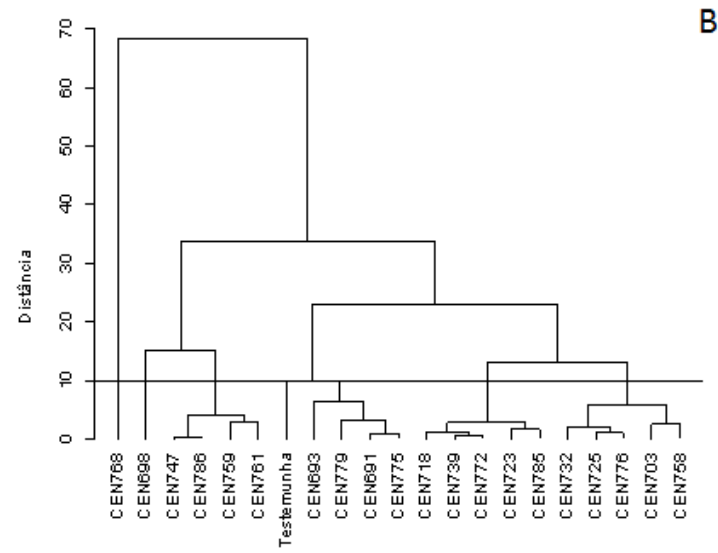

Comp. médio de silhueta: 0,6247 holust( (". "average")

Figura 4. Dendograma do agrupamento dos isolados de Trichoderma que inibiram Sclerotium rolfsii (A) e Verticillium dahliae (B) pela produção de metabólitos não-voláteis

A

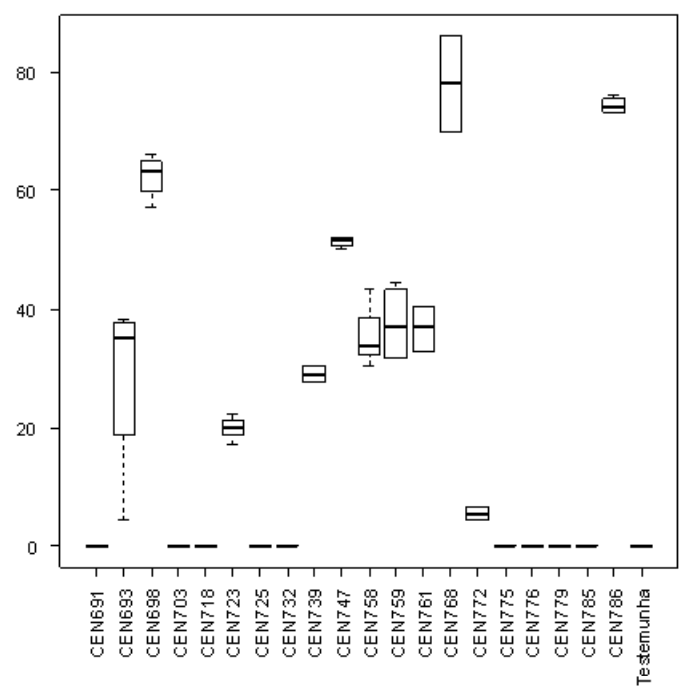

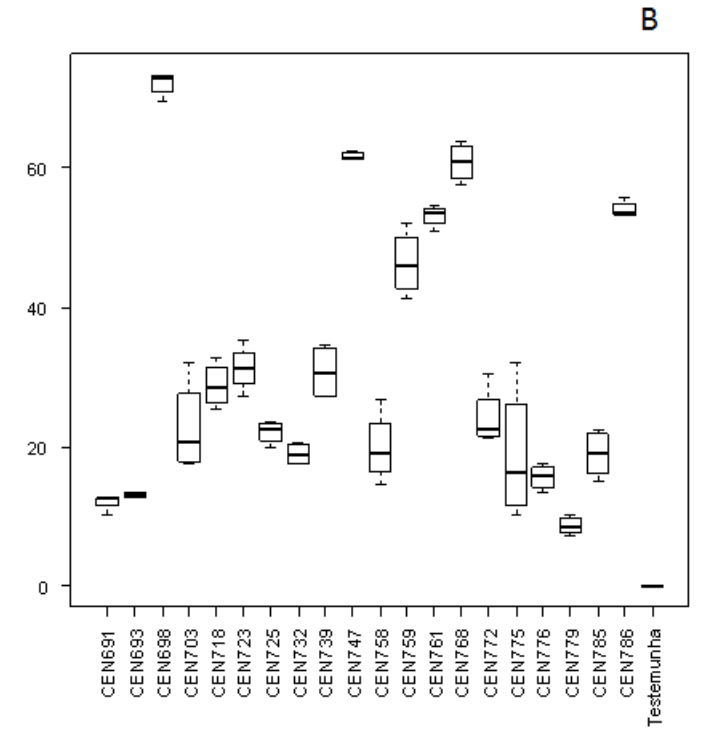

Figura 5. Boxplot do percentual de inibição de Sclerotium rolfsii (A) e Verticillium dahliae (B) por metabólitos não-voláteis termoestáveis produzidos por isolados de Trichoderma.

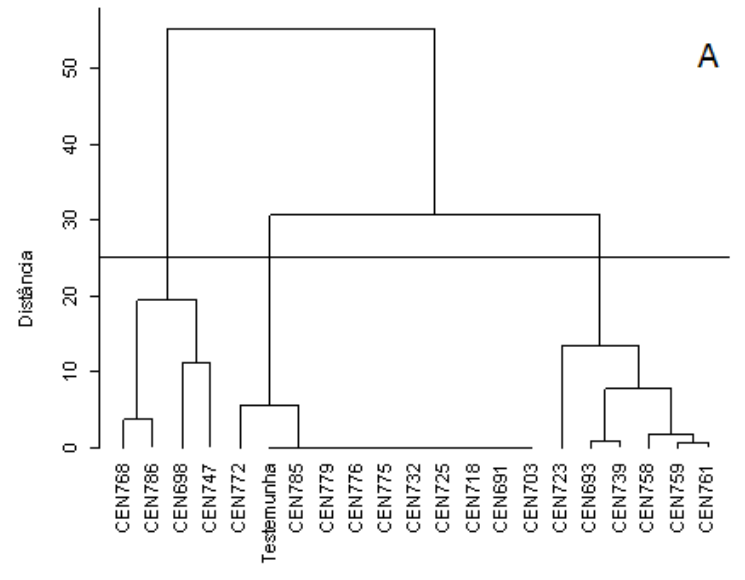

Comp. médio de silhueta: 0,7951 hclust (", "average")

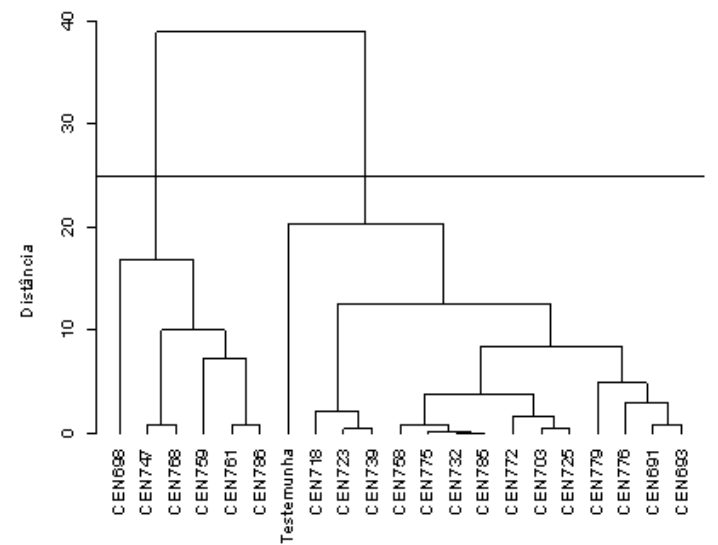

Comp. médio de silhueta: 0.7349 helust (". "average")

Figura 6. Dendograma do agrupamento dos isolados de Trichoderma que inibiram Sclerotium rolfsii (A) e Verticillium dahliae (B) pela produção de metabólitos não-voláteis termoestáveis 
Tabela 2. Médias $(\%) \pm$ desvios padrão da inibição de $S$. rolfsii por metabólitos voláteis, não-voláteis e não voláteis termoestáveis produzidos por isolados de Trichoderma spp.

\begin{tabular}{|c|c|c|c|}
\hline & \multicolumn{3}{|c|}{ Sclerotium rolfsii } \\
\hline & Voláteis & Não-Voláteis & Não-Voláteis Termoestáveis \\
\hline CEN691 & $46,38 \pm 5,16 \mathrm{a}$ & $0 \mathrm{~b}$ & 0 \\
\hline CEN693 & $43,85 \pm 2,36 \mathrm{a}$ & $5,22 \pm 0,55 \mathrm{bB}$ & $28,3 \pm 16,08 \mathrm{~A}$ \\
\hline CEN698 & $61,37 \pm 2,81 \mathrm{a}$ & $62,45 \pm 1,92 \mathrm{aA}$ & $62,45 \pm 3,78 \mathrm{~A}$ \\
\hline CEN703 & $44,95 \pm 3,71 \mathrm{~b}$ & $61,35 \pm 2,64 \mathrm{aA}$ & $0 \mathrm{~B}$ \\
\hline CEN718 & $50,38 \pm 2,98 \mathrm{a}$ & $42,02 \pm 4,48 \mathrm{bB}$ & $0 \mathrm{~B}$ \\
\hline CEN723 & $52,17 \pm 6,17 \mathrm{a}$ & $16,77 \pm 6,56 \mathrm{bA}$ & $19,85 \pm 2,05 \mathrm{~A}$ \\
\hline CEN725 & $67,57 \pm 1,43 b$ & $100 \pm 0,0 \mathrm{Aa}$ & $0 \mathrm{~B}$ \\
\hline CEN732 & $55,8 \pm 5,96 \mathrm{a}$ & $0 \mathrm{~b}$ & 0 \\
\hline CEN739 & $45,23 \pm 6,88 \mathrm{a}$ & $10,93 \pm 1,6 \mathrm{bA}$ & $29,1 \pm 1,62 \mathrm{~A}$ \\
\hline CEN747 & $61,05 \pm 3,96 \mathrm{a}$ & $48,98 \pm 5,66 \mathrm{bA}$ & $51,35 \pm 0,94 \mathrm{~A}$ \\
\hline CEN758 & $56,48 \pm 2,86 \mathrm{a}$ & $32,17 \pm 4,12 \mathrm{bA}$ & $35,35 \pm 5,52 \mathrm{~A}$ \\
\hline CEN759 & $59,55 \pm 10,1 \mathrm{a}$ & $30,53 \pm 2,15 \mathrm{bA}$ & $37,45 \pm 6,81 \mathrm{~A}$ \\
\hline CEN761 & $52,88 \pm 5,37 \mathrm{a}$ & $35,1 \pm 4,01 \mathrm{bA}$ & $36,75 \pm 4,34 \mathrm{~A}$ \\
\hline CEN768 & $61,47 \pm 4,95 b$ & $100 \pm 0,0 \mathrm{aA}$ & $78,05 \pm 9,3 \mathrm{~B}$ \\
\hline CEN772 & $44,3 \pm 4,22 b$ & $59,65 \pm 0,98 \mathrm{aA}$ & $5,5 \pm 1,27 \mathrm{~B}$ \\
\hline CEN775 & $44,00 \pm 3,7 \mathrm{a}$ & $0 \mathrm{~b}$ & 0 \\
\hline CEN776 & $67,74 \pm 1,32 \mathrm{a}$ & $32,17 \pm 1,73 \mathrm{bA}$ & $0 \mathrm{~B}$ \\
\hline CEN779 & $38,98 \pm 2,35 \mathrm{a}$ & $0 \mathrm{~b}$ & 0 \\
\hline CEN785 & $49,84 \pm 1,22 \mathrm{a}$ & $0 \mathrm{~b}$ & 0 \\
\hline CEN786 & $66,2 \pm 3,64 \mathrm{a}$ & $40,22 \pm 2,6 \mathrm{bB}$ & $74,42 \pm 1,37 \mathrm{~A}$ \\
\hline Testemunha & 0 & 0 & 0 \\
\hline
\end{tabular}

Letras minúsculas iguais mostram que o isolado não difere quanto à inibição do patógeno volátil e não-volátil, e letras maiúsculas iguais mostram que o isolado não difere quanto a inibição do patógeno não-volátil e não-volátil termoestável, segundo o teste de Tukey, ao nível de 5\% de significância estatística.

aqueles superiores aos $40 \%$. Dado o valor de 0,7349 para o comprimento médio de silhueta, considerou-se que a estrutura de agrupamentos encontrada foi forte (Figura 6B).

\section{Metabólitos voláteis vs não-voláteis}

A proporção média de inibição do patógeno $S$. rolfsii entre metabólitos voláteis e não-voláteis foi estatisticamente igual apenas para o isolado CEN698 (T. koningiopsis), como mostrado na Tabela 2. Para $V$. dahliae, com exceção da testemunha, todos apresentaram diferença significativa entre metabólitos voláteis e não-voláteis (Tabela 3).

\section{Metabólitos não voláteis vs não-voláteis termoestáveis}

Ao nível de 5\% de significância estatística, a ação dos metabólitos não-voláteis e não-voláteis termoestáveis não difere para os isolados CEN698, CEN 723, CEN 758 e CEN 759 (T. koningiopsis) e CEN 747e CEN 761 (T. asperellum) na inibição de S. rolfsii. O mesmo resultado foi verificado na ação desses metabólitos em relação à inibição de $V$. dahliae, para os isolados CEN761 e CEN786 (T. asperellum); CEN725 e CEN732 (T. harzianum); CEN703, CEN739 e CEN759 (T. koningiopsis). As Tabelas 2 e 3 mostram as proporções médias de inibição desses patógenos seguidas do desvio padrão para cada isolado do agente de biocontrole.

\section{DISCUSSÃO}

Os fungos do gênero Trichoderma utilizam, para sua sobrevivência e proliferação, diferentes mecanismos de ação contra seus competidores, incluindo ação direta e degradação e uso de carboidratos complexos (12), que os tornam um dos mais bem sucedido colonizadores dos seus habitats, quer pela utilização eficiente de substrato, quer pela capacidade de secreção de metabólitos (24).

A maior inibição de crescimento micelial de $V$. dahliae a 19 isolados de Trichoderma em relação a $S$. rolfsii, que foi inibido em grau máximo por apenas um dos isolados, pode estar relacionada à origem dos isolados de Trichoderma, já que os mesmos foram obtidos de rizosfera/solo da cultura do morango (26). Como $V$. dahliae foi isolado de morango infectado e $S$. rolfsii de áster, pode-se supor que os isolados de Trichoderma provenientes de morango tenham uma ação mais efetiva do que os provenientes de outras culturas, ou que $S$. rolfsii apresente estratégia de defesa mais eficaz. Segundo Duffy et al (9) os antagonistas utilizam diferentes mecanismos de domínio nas interações com patógenos, esses por sua vez têm surpreendentemente diversas respostas para neutralizar o antagonismo. Howell (13) menciona que, 
Tabela 3. Médias (\%) \pm desvios padrão da inibição de $V$. dahliae por metabólitos voláteis, não-voláteis e não voláteis termoestáveis produzidos por isolados de Trichoderma spp.

\begin{tabular}{|c|c|c|c|}
\hline & \multicolumn{3}{|c|}{ Verticillium dahliae } \\
\hline & \multirow{2}{*}{ Voláteis } & \multirow{2}{*}{ Não-Voláteis } & Não-Voláteis \\
\hline & & & Termoestáveis \\
\hline CEN691 & $82,27 \pm 6,61 \mathrm{a}$ & $6,66 \pm 0,0 \mathrm{bB}$ & $12,12 \pm 1,21 \mathrm{~A}$ \\
\hline CEN693 & $81,21 \pm 0,49 \mathrm{a}$ & $14,53 \pm 1,0 \mathrm{bA}$ & $13,01 \pm 0,33 \mathrm{~B}$ \\
\hline CEN698 & $80,45 \pm 1,03 \mathrm{a}$ & $68,94 \pm 0,58 \mathrm{bB}$ & $72,15 \pm 1,74 \mathrm{~A}$ \\
\hline CEN703 & $81,21 \pm 1,4 \mathrm{a}$ & $29,09 \pm 4,23 \mathrm{bA}$ & $22,73 \pm 6,72 \mathrm{~B}$ \\
\hline CEN718 & $82,42 \pm 0,86 \mathrm{a}$ & $36,97 \pm 4,11 \mathrm{bA}$ & $28,84 \pm 3,17 \mathrm{~B}$ \\
\hline CEN723 & $81,96 \pm 0,3 \mathrm{a}$ & $39,69 \pm 2,64 \mathrm{bA}$ & $31,21 \pm 3,23 \mathrm{~B}$ \\
\hline CEN725 & $79,69 \pm 2,13 \mathrm{a}$ & $23,02 \pm 3,5 \mathrm{bA}$ & $22,12 \pm 1,6 \mathrm{~A}$ \\
\hline CEN732 & $79,39 \pm 1,11 \mathrm{a}$ & $20,6 \pm 12,99 \mathrm{bA}$ & $18,94 \pm 1,6 \mathrm{~A}$ \\
\hline CEN739 & $81,36 \pm 0,58 \mathrm{a}$ & $35,6 \pm 5,25 \mathrm{bA}$ & $30,75 \pm 4,03 \mathrm{~A}$ \\
\hline CEN747 & $80,91 \pm 2,35 \mathrm{a}$ & $55,9 \pm 1,03 \mathrm{bB}$ & $61,66 \pm 0,58 \mathrm{~A}$ \\
\hline CEN758 & $82,12 \pm 0,61 \mathrm{a}$ & $26,51 \pm 3,82 \mathrm{bA}$ & $19,83 \pm 5,05 \mathrm{~B}$ \\
\hline CEN759 & $80,45 \pm 2,98 \mathrm{a}$ & $50,6 \pm 0,35 \mathrm{bA}$ & $46,36 \pm 4,71 \mathrm{~A}$ \\
\hline CEN761 & $79,54 \pm 1,74 \mathrm{a}$ & $53,33 \pm 2,62 \mathrm{bA}$ & $53,17 \pm 1,6 \mathrm{~A}$ \\
\hline CEN768 & $81,66 \pm 1,25 b$ & $100 \pm 0,0 \mathrm{aA}$ & $60,75 \pm 2,77 \mathrm{~B}$ \\
\hline CEN772 & $81,05 \pm 0,58 \mathrm{a}$ & $36,2 \pm 3,68 \mathrm{bA}$ & $24,09 \pm 4,21 \mathrm{~B}$ \\
\hline CEN775 & $77,87 \pm 2,07 \mathrm{a}$ & $7,42 \pm 0,91 \mathrm{bB}$ & $18,79 \pm 9,8 \mathrm{~A}$ \\
\hline CEN776 & $80,15 \pm 1,94 \mathrm{a}$ & $21,96 \pm 0,76 \mathrm{bA}$ & $15,6 \pm 1,82 \mathrm{~B}$ \\
\hline CEN779 & $79,54 \pm 0,76 \mathrm{a}$ & $10,3 \pm 0,49 \mathrm{bA}$ & $8,63 \pm 1,35 \mathrm{~B}$ \\
\hline CEN785 & $80,45 \pm 1,03 \mathrm{a}$ & $38,18 \pm 2,62 \mathrm{bA}$ & $18,94 \pm 3,44 \mathrm{~B}$ \\
\hline CEN786 & $79,84 \pm 2,06 \mathrm{a}$ & $56,21 \pm 2,39 \mathrm{bA}$ & $54,09 \pm 1,15 \mathrm{~A}$ \\
\hline Testemunha & 0 & 0 & 0 \\
\hline
\end{tabular}

Letras minúsculas iguais mostram que o isolado não difere quanto à inibição do patógeno volátil e não-volátil, e letras maiúsculas iguais mostram que o isolado não difere quanto a inibição do patógeno não-volátil e não-volátil termoestável, segundo o teste de Tukey, ao nível de 5\% de significância estatística.

talvez, o melhor método para obter um potencial agente de biocontrole seja isolar espécies de Trichoderma de áreas de solos e plantas onde a doença esteja ocorrendo. O ensaio de cultura pareada é importante para selecionar isolados que tenham maior atividade antagônica e de micoparasitismo (17).

Apesar de o crescimento e o enrolamento de hifas serem importantes na interação parasítica, por si só não garantem sucesso no controle biológico (2). Alguns autores mencionam que a ação sinergística atribuída à produção de enzimas e antibióticos, simultaneamente, possa explicar esse sucesso. O principal interesse é naqueles compostos que apresentam atividade antibiótica e que, provavelmente, estão implicados na eficácia do isolado em atuar como agente de biocontrole (22).

A variedade e o número de compostos encontrados no metaboloma de espécies de Trichoderma são surpreendentemente altos e incluem enzimas líticas e hormônios, além de muitos metabólitos secundários com importantes funções biológicas (15). Em 90\% das aplicações de antagonistas no controle de fungos fitopatogênicos têm sido utilizadas diferentes linhagens/espécies de Trichoderma (5) e a antibiose tem sido considerada um dos principais mecanismos de ação desses microrganismos (22).

$\mathrm{Na}$ avaliação da suscetibilidade de $S$. rolfsii e $V$. dahliae aos metabólitos secundários voláteis, não-voláteis e não-voláteis termoestáveis secretados pelos isolados de Trichoderma testados, verificou-se uma variação no percentual de inibição do crescimento micelial desses patógenos, dependendo do metabólito avaliado (Figuras 1,3 e 5). Os resultados mostraram que $V$. dahliae foi mais suscetível a ação dos metabólitos produzidos pelos isolados de Trichoderma, com inibição acima de $70 \%$, do que $S$. rolfsii, em que os metabólitos nãovoláteis de cinco isolados e os metabólitos não-voláteis termoestáveis de nove isolados não influíram em seu crescimento (Figuras $3 \mathrm{e}$ 5). Esses dados confirmam a maior interação antagônica verificada nos estudos de pareamento anteriormente discutidos (Tabela 1). No teste de termoestabilidade, apesar de ter havido uma diminuição nas porcentagens de inibição, os metabólitos de Trichoderma spp. se mantiveram ativos mesmo após autoclavagem, pois inibiram o crescimento micelial dos patógenos, indicando o potencial desses metabólitos antifúngicos, nas condições experimentais utilizadas.

Diversos estudos têm mencionado variação de sensibilidade dos fungos fitopatogênicos a metabólitos produzidos por antagonistas (9). Segundo Martin-Corder \& Melo (16), a capacidade de Trichoderma produzir metabólitos secundários e o seu efeito fungicida pode variar entre espécies, entre isolados da mesma espécie (27) e em função 
dos compostos antifúngicos secretados (15). Análises qualitativas e quantitativas de metabólitos produzidos por diferentes isolados de Trichoderma são muito importantes para selecionar os biologicamente ativos (10). Na realidade, os mecanismos empregados pelos agentes de biocontrole são muitos complexos e sua ação varia de acordo com o tipo de agente de biocontrole, do patógeno e da planta hospedeira envolvida na interação (13). A aplicação dos metabólitos de Trichoderma, obtidos via cultivo massal desses fungos ou por meio de síntese química, pode viabilizar a obtenção de novos biofertilizantes e biopesticidas baseado em compostos bioativos. Isto poderia ter um efeito benéfico significativo no impacto sobre o manejo de doenças em plantas (30).

O entendimento dos mecanismos de ação envolvido no antagonismo de isolados Trichoderma sobre fitopatógenos é importante para a seleção de agentes de biocontrole eficientes, sem esquecer que esse potencial deve ser também avaliado em condições de campo, pois o nível de controle biológico de um patógeno pode variar em função do agente de biocontrole utilizado e sua capacidade de adaptação às condições bióticas e abióticas $(7,8)$, dentro e entre espécies de Trichoderma.

\section{REFERÊNCIAS BIBLIOGRÁFICAS}

1. Akram, A.; Iqbal, S.M.; Qureshi, R.A.; Rauf, C.A. Variability among isolates of Sclerotium rolfsii associated with collar rot disease of chickpea in Pakistan. Pakistan Journal Botanic, Islamabad, v. 40, n. 1, p. 453-460, 2008.

2. Almeida, F.B.; Cerqueira, F.M.; Silva, R. do N.; Ulhoa, C.J.; Lima, A.L. Mycoparasitism studies of Trichoderma harzianum strains against Rhizoctonia solani: evaluation of coiling and hydrolytic enzyme production. Biotechnology Letters, Heidelberg, v. 29, n. 8, p. 1189-93, 2007.

3. Amin, F.; Razdan, V.K.; F. A. Mohiddin, F.A.; Bhat, K.A.; Sheikh, P.A. Effect of volatile metabolites of Trichoderma species against seven fungal plant pathogens in-vitro. Journal of Phytology, Humnabad, v. 2, n. 10, p. 34-37, 2010.

4. Bell, D.K.; Wells, H.D.; Markhan, C.R. In vitro antagonism of Trichoder$m a$ species against six fungal pathogens. Phytopathology, St. Paul, v. 72, p. 379-382, 1982.

5. Benítez, T.; Rincón, A.M.; M., Limón, M.C.; Codón, A.C. Biocontrol mechanisms of Trichoderma strains. International Microbiology, Barcelona, v. 7, p. 249-260, 2004.

6. Bosah, O.; Igeleke, C.A.; Omorusi, V.I. In Vitro Microbial control of pathogenic Sclerotium rolfsii. International Journal of Agriculture \& Biology, Faisalabad, v. 12, p.474-476, 2010.

7. Dennis, C.; Webster, J. Antagonistic properties of species-groups of Trichoderma. III. Hyphal interactions. Transactions British Mycological Society, Manchester, v. 57, n. 1, p. 363-369, 1971a.

8. Dennis, C.; Webster, J. Antagonistic properties of species-groups of Trichoderma. II. Production of volatile antibiotics. Transactions British Mycological Society, Manchester, v. 57, n. 11, p. 41-48, 1971b.

9. Duffy, B.; Schouten, A.; Raaijmakers, J.M. Pathogen Self-Defense: mechanisms to counteract microbial antagonism. Annual Review Phytopathology, Palo Alto, v. 41, p.501-538, 2003.

10. El-Hassan, A.; Walker, F.; Schöne, J.; Buchenauer, H. Detection of viridiofungin A and other antifungal metabolites excreted by Trichoderma harzianum active against different plant pathogens. European Journal of Plant Patholology, New York, v. 124, p. 457-470, 2009.

11. Grunden, E.; Chen, W.; Crane, J.L. Fungi colonizing microsclerotia of Verticillium dahliae in urban environments. Fungal Diversity, Chiang Rai, v. 8, p. 129-141, 2001.
12. Harman, G.E.; Howell, C.R.; Viterbo, A.; Chet, I.; Lorito, M. Trichoderma species - opportunistic, avirulent plant symbionts. Nature reviews/Microbiology, London, v. 2, n.1, p. 43-56, 2004.

13. Howell, C. R. Mechanisms employed by Trichoderma species in the biological control of plant diseases: The History and evolution of current concepts. Plant Disease, St. Paul, v.87, p. 4-10, 2003.

14. Kupper, K.C.; Gimenes-Fernandes, N.; Goes, A. Controle biológico de Colletotrichum acutatum, agente causal da queda prematura dos frutos cítricos. Fitopatologia Brasileira, Viçosa, v. 28, n. 3, p. 251-257, 2003.

15. Lorito, M.; Woo, S.L.; Harman, G.E.; Monte, E. Translational research on Trichoderma: from 'omics to the field. Annual Review Phytopathology, Palo Alto, v. 498, p. 395-417, 2010.

16. Martins-Corder, M.P.; Melo, I.S. Antagonismo "in vitro" de Trichoderma spp. a Verticillium dahliae Kleb. Scientia Agrícola, Piracicaba, v. 55, p. 1-7, 1998.

17. Mello, S.C.M.; Ávila, Z.R.; Braúna, L.M.; Pádua, R.R.; Gomes, D. Cepas de Trichoderma spp. para el control biológico de Sclerotium rolfsii Sacc. Fitosanidad, Habana, v. 11, n. 1, p. 3-9, 2007.

18. Mohiddin, F.A.; Khan, M.R.; Khan, S.M.; Bhat, B.H. Why Trichoderma is considered super hero (super fungus) against the evil parasites? Plant Pathology Journal, Dübendorf, v. 9, p. 92-102, 2010.

19. Mukherjee, P.K.; Horwitz, B.A.; Kenerley, C.M. Secondary metabolism in Trichoderma - a genomic perspective. Microbiology, Washington, v. 158, p. 35-45, 2012

20. Otero, L.; Ducasse, D.; Miller, R.N.G. Variability in ribosomal DNA genic and spacer regions in Verticillium dahliae isolates from different hosts. Fitopatologia Brasileira, Viçosa, v. 29, p. 441-446, 2004.

21. Rajendiran, R.; Jegadeeshkumar, D.; Sureshkumar, B.T.; Nisha, T. In vitro assessment of antagonistic activity of Trichoderma viride against post harvest pathogens. Journal of Agricultural Technology, Bangkok, v. 6, n. 1, v. 31-35, 2010.

22. Reino, J.L.; Guerrero, R.F.; Hernández-Galán R.; Collado, I.G. Secondary metabolites from species of the biocontrol agent Trichoderma. Phytochemistry Reviews, New York, v. 7, p. 89-123, 2008.

23. Reis, A.; Boiteuk, L.S. Círculo de hospedeiras de isolados de Verticillium dahliae obtidos de tomateiro, quiabeiro e morangueiro. 1ed., Brasília, DF: Embrapa Hortaliças, 2006. 16p.

24. Schuster, A.; Schmoll, M. Biology and biotechnology of Trichoderma. Applied Microbiology and Biotechnology, New York, v. 87, p. 787-799, 2010.

25. Serra, I.M.R.S.; Silva, G.S. Caracterização biológica e fisiológica de isolados de Sclerotium rolfsii obtidos de pimentão no estado do Maranhão. Fitopatologia Brasileira, Viçosa, v. 30, p. 61-66, 2005.

26. Silva, K.F.A.S.; Michereff Filho, M.; Silva, J.B.T.; Martins, I.; Isaias, C.O.; Resende, F.V., Liz, R.S.; Barboza, E.A.; Mello, S.C.M. Dinâmica populacional de fungos benéficos em solos nos sistemas de cultivo convencional e orgânico de morangueiro. Brasília, DF: Embrapa Hortaliças, 2009. 25p (Boletim de Pesquisa e Desenvolvimento, 60).

27. Sivasithamparam, K.; Ghisalberti, E.L. Secondary metabolism in Trichoderma and Gliocladium. In: Harman, G.E.; Kubicek, C.P. Trichoderma and Gliocladium. Harman, G.E. and Kubicek, C.P. London: Taylor and Francis Ltd, 1998. v. 1, p. 139-191.

28. Stoppacher, N.; Kluger, B.; Zeilinger, S.; Krska, R.; Schuhmacher, R. Identification and profiling of volatile metabolites of the biocontrol fungus Trichoderma atroviride by HS-SPME-GC-MS. Journal of Microbiological Methods, Philadelphia, v. 81, n. 2, p.187-193, 2010.

29. Vinale, F.; Sivasithamparam, K.; Ghisalberti. E.L.; Marra, R.; Sheridan L. Woo, S.L.; Lorito, M. 2008. Trichoderma-plant-pathogen interactions. Soil Biology \& Biochemistry, Philadelphia, v. 40, p. 1-10, 2008.

30. Vinale, F.; Ghisalberti. E.L.; Sivasithamparam, K.; Marra, R.; Ritieni, A.; Ferracane, R.; Woo, S.; Lorito, M. Factors affecting the production of Trichoderma harzianum secondary metabolites during the interaction with different plant pathogens. Letters in Applied Microbiology, New Jersey, v. 48, p. 705-711, 2009. 